\title{
Kinetic Energy Recovery System for Vehicle Suspension
}

\author{
Suhail A. Wani \\ Department of Mechanical Engineering \\ D.Y Patil College of Engineering \\ Pune, Maharashtra, India
}

\begin{abstract}
Vehicle is a very important part of human life. It makes transportation easy. Although there have been many inventions and on-going researches on increasing engine efficiency, there exist other opportunities to increase the comprehensive performance of vehicles. In application, various losses occur in different sections of the vehicle. They can be identified as frictional losses, losses due to air drag, losses due to vibrations, thermal losses, etc. One of the losses is the dissipation of energy by the shock absorber or suspension of a vehicle. Moving vehicles can expend a significant amount of energy in undesirable vertical motions that are induced by road bumps and much of that is dissipated in conventional shock absorbers as they dampen the vertical motions. This paper relates to an energy recovery model, more particularly, to an apparatus that uses the kinetic energy of automobile suspension and stores it in the form of electrical energy. The proposed study uses a rack and pinion mechanism to utilize the linear motion of a telescopic suspension. The arrangement works such that the linear movement of the suspension is converted to rotatory motion. The rotational mechanical energy generated by the mechanism is used to produce electrical energy by a dynamometer and is stored using a power bank. The study validates the practicality of the system and prove it to be an effective clean energy generation mechanism for future automobiles.
\end{abstract}

Keywords - Thermal losses; kinetic energy; rack and pinion; shock absorber.

\section{INTRODUCTION}

The suspension system is one of the most important components of a vehicle. It consists of tires, springs, linkages, shock absorber, struts, and other parts according to the specification of the vehicle. A shock absorber is a part of the suspension system that is designed to smooth out or damp shock impulse, and convert kinetic energy to another form of energy (usually thermal energy, which can be easily dissipated by the fluid inside shock absorbers). Ideally, a shock absorber is a damper that is designed to damp shock impulses generated in a moving vehicle. On application, the shock absorbers of a vehicle undergo linear movements that are otherwise not utilized as such. The idea of saving energy came into light from the $20^{\text {th }}$ century. Since then the concept of energy efficiency has gained attention in the automobile industry. Therefore, unlike traditional energy-regenerative suspension, which can only absorb vibration passively, the energy regenerative suspension system is being introduced which can be used to store in the form of electrical energy. A regenerative suspension system can be used in the suspension assembly to attenuate or eliminate the energy generated by the excitation vibration in the vertical direction. This system can be used to convert mechanical energy into electromagnetic energy through a rack and pinion mechanism, and the electromagnetic energy is stored by energy storage elements, which can reduce vibration and recover excess energy. After extensive research of over 40 years, the system has been introduced in hybrid and pure electric vehicles, and it greatly improves fuel economy as a whole. Considerable research has been conducted on the energy recovery potential of vehicle suspension. However, the specific value of energy recovery differs. For example, [1] indicated that the energy recovery of the entire vehicle suspension system is only $46 \mathrm{~W}$, whereas [2] reported that the energy of $7500 \mathrm{~W}$ can be recovered in the suspension of a passenger vehicle. Therefore, the amount of energy that can be extracted follows the type of setup that is used. This paper relates to the idea of developing a suspension based kinetic energy recovery system that uses a simple rack and pinion assembly to convert the reciprocating linear motion of the suspension and into rotatory motion, which can be used for generation of electricity via a generator.
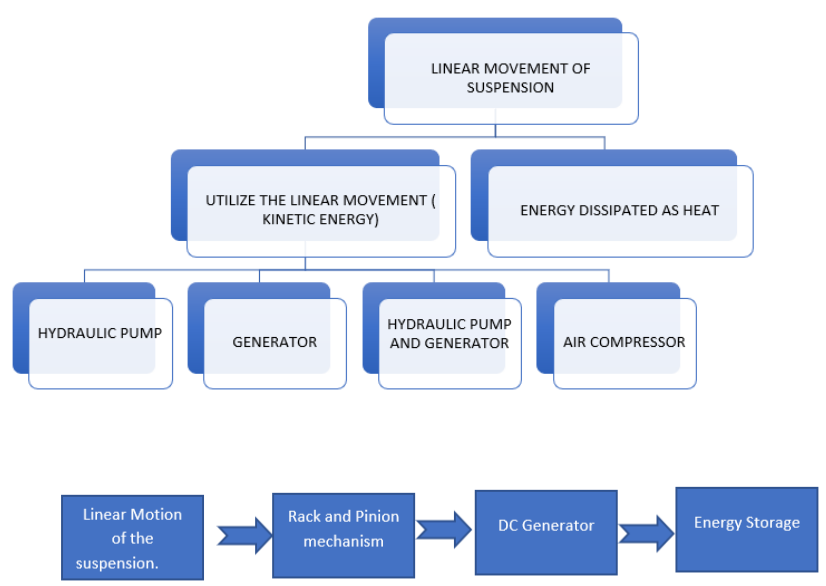

Fig 1. BLOCK DIAGRAM 


\section{COMPONENTS}

\section{A. Rack and Pinion Assembly}

A rack and pinion mechanism is used to transform rotary motion into linear motion and vice versa. A round spur gear called as the pinion meshes with a spur gear which has teeth set in a straight line, the rack, is a type of linear which converts rotational motion into linear motion. The linear motion of the rack causes the pinion to rotate, thereby translating the linear to motion to rotatory motion.

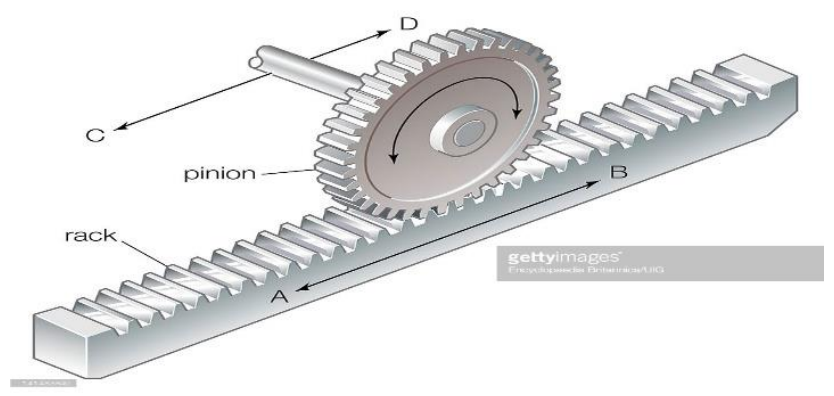

Fig 2: Rack and Pinion

\section{B. DC Generator}

An electrical generator is a device that converts mechanical energy to electrical energy. A generator forces electric charge (usually carried by electrons) to flow through an external electrical circuit. It can be deemed analogous to a water pump, which pumps water throughout the network of pipes. The source of rotational energy may be a reciprocating or turbine steam engine, water falling through a turbine or waterwheel, an internal combustion engine, a wind turbine, a hand crank, compressed air or any other source of mechanical energy. In our study the source of rotation is the shaft driven by the pinion gear.

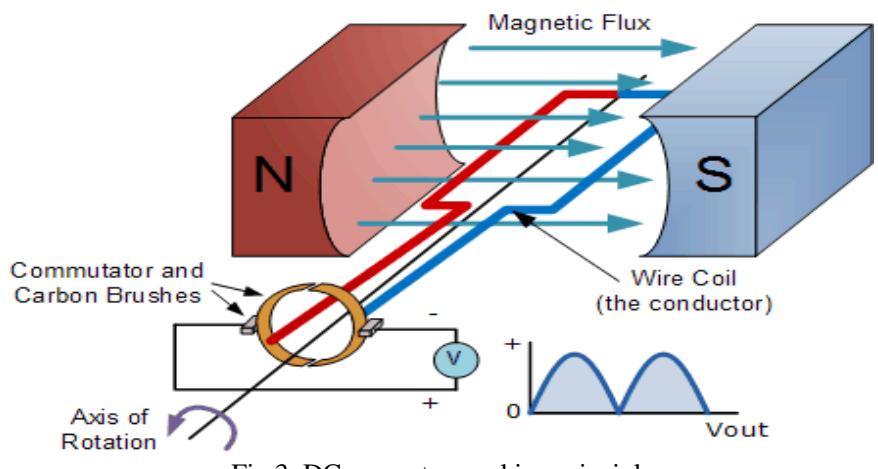

Fig 3: DC generator working principle

The following are the specification of the DC Generator used in this project.

Generator output: $6 \mathrm{~V}-20 \mathrm{~V}$

Output Current: $\sim 0.5-1 \mathrm{amp}$

Motor RPM: 20-30 RPM

The motor selection is limited due to various constraints in the current project. The RPM achieved is relatively low and also the mounting of the motor also bears some dimension constraints. Therefore, as per the criteria, the motor selected has a small dimension and RPM in the 20-30 range.

\section{Capacitor}

A capacitor is an electronic component that stores electric charge. It is made up of two conductors that are placed in proximity to each other and are separated by a dielectric material. The plates accumulate electric charges when connected to a power source. The charges accumulate such that one of the plates accumulates positive charge whereas the other plate accumulates a negative charge.

The capacity of a capacitor is denoted by its capacitance. Capacitance is defined as the amount of electric charge that is stored in the capacitor at a voltage of 1 Volt. It is measured in units of Farad (F). In this study capacitors are used to store the electrical energy produced by the generator. Further, the selection can be based on factors such as cost, average and maximum power demand at the application site, availability of space at the installation site, etc.

\section{SETUP AND CALCULATIONS}

\section{A. Setup}

The regenerative shock absorber converts this kinetic energy into electricity instead of heat through the use of a Linear Motion Electromagnetic System. Shock absorbers are installed between chassis and wheels to suppress the vibration, mainly induced by road roughness, to compensate for bumpy roads and provide riding comfort. The rack and pinion is installed on the shock absorber. From the study in [3] and [4] the linear motion of the rack per second can be estimated to be $89 \mathrm{~mm}$ per second, which can be translated to 24 RPM by the rack and pinion setup. The RPM achieved is used to drive a DC generator mounted in the assembly. Through this electromechanical system, electricity is generated. The electricity generated can be stored in a capacitor which can be further extracted through the controlled extraction process [4] or any conventional extraction process.

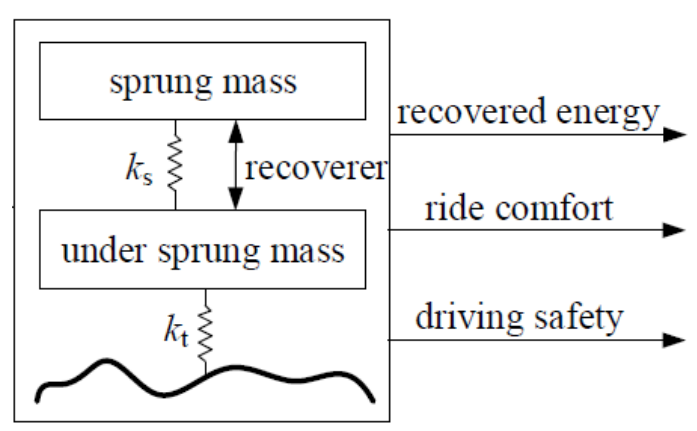

Fig 4. Regenerative Suspension Model 

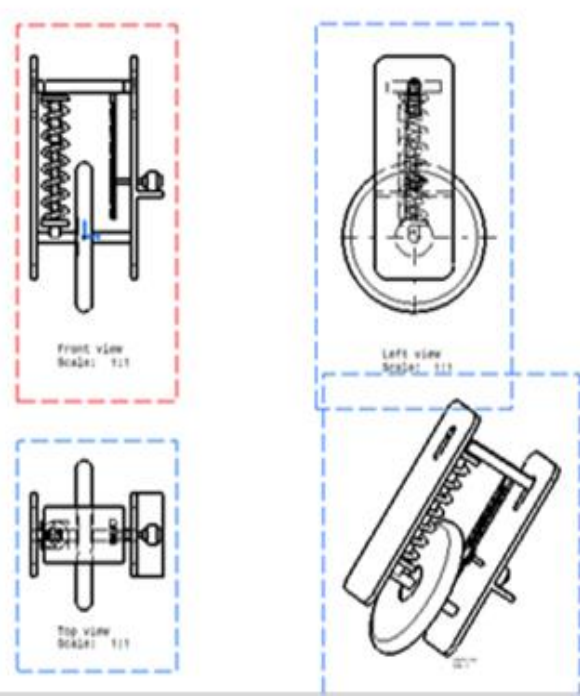

Fig 5. CATIA drawing

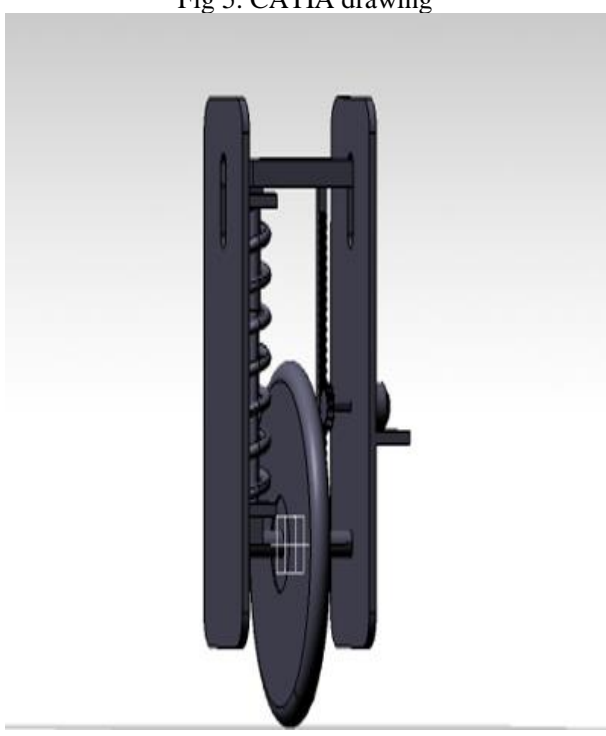

Fig 6. CATIA drawing

\section{B. Calculations}

RPM requirement of the generator

RPM requirement of the generator $=30 \mathrm{RPM}$

Velocity at the contact point of rack and pinion $=89 \frac{\mathrm{mm}}{\mathrm{s}}$

At contact point

$V_{\text {rack }}=V_{\text {pinion }}$

$V_{\text {rack }}=\omega_{p} r_{p}$

$V_{\text {rack }}=\left(\frac{2 \pi N}{60}\right) r_{p}$

Substituting the values of $V_{\text {rack }}, N$

$$
\begin{aligned}
& 89 \frac{\mathrm{mm}}{s}\left(=\frac{2 \pi(30)}{60 \mathrm{~s}}\right) r_{p} \\
& r_{p}=28.3 \mathrm{~mm}
\end{aligned}
$$

Calculations using minimum RPM required by the generator.

Minimum RPM requirement of the generator $=25 \mathrm{RPM}$

Velocity at the contact point of rack and pinion $=89 \frac{\mathrm{mm}}{\mathrm{s}}$

Substituting the values of $V_{\text {rack }}, N_{\min }$

$$
\begin{aligned}
& 89 \frac{\mathrm{mm}}{\mathrm{s}}\left(=\frac{2 \pi(25)}{60 \mathrm{~s}}\right) r_{p} \\
& r_{p}=33 \mathrm{~mm}
\end{aligned}
$$

Therefore,

$\mathrm{d}_{p}=66 \mathrm{~mm}$

Therefore, the following is the specification of the pinion selected in this setup.

$$
d_{p}=66 \mathrm{~mm}
$$

$\mathrm{m}=1.5$

Number of teeth $=44$

Diametral Pitch $(P)=N / D=44 / 66=0.66 \mathrm{~mm}$

Addendum $(a)=1 / P=1 / 0.66=1.515 \mathrm{~mm}$

Dedendum $(b)=1.157 / P=1.157 / 0.66=1.753 \mathrm{~mm}$

Tooth Thickness $=1.5708 / P=1.5708 / 0.66=2.37 \mathrm{~mm}$

Whole Depth $=2.157 / P=2.157 / 0.66=3.268 \mathrm{~mm}$

Clearance $=0.157 / P=0.157 / 0.66=0.237 \mathrm{~mm}$

Minimum Length of rack

$$
\begin{aligned}
\text { Minimum Length of rack } & =2 \pi(r+a) \\
& =2(\pi)(33+1.515) \\
& =216.86 \mathrm{~mm}
\end{aligned}
$$

\section{REMARKS}

\section{A. Conflict}

The primary purpose of suspension is to provide ride comfort and handling stability. The system adopted in this paper relates to the Passive suspension. As the active suspension is known for providing the best vibration control although it consumes lots of energy, while the adaptation of the rack and pinion is in a passive system, whose control performance is not excellent as that of the active system. To provide the optimum performance of such a system further design iteration is required to incorporate it into an active system.

\section{B. Efficiency}

It is important to define maximize the efficiency of the regenerative model. For the absence of a speed increaser, the 
system has a low energy recovery efficiency. The RPM achieved at the shaft is limited since no additional gears are used. However, it is evident from the data [1] that much higher rotational speeds can be achieved by using multiple gear system. Also, the space availability is limited since the whole system has to be installed between the tire and the chassis of the vehicle. The efficiency of the system thus depends on factors such as available space, average movement of the shock absorber, effectiveness of Dynamometer, etc.

\section{Reliability}

Reliability is a key factor for engineering applications. The reliability of the system depends on the working parameters, material used, area of application, etc. The system designed is limited to certain levels of loads, driving forces, and other inputs. The reliability of the whole system also varies with physical conditions such as road conditions, temperature and humidity, maintenance of the vehicle, etc.

TABLE I. Survey of conducted simulation-based testing for regenerative energy systems [8]

\begin{tabular}{|c|c|c|c|c|}
\hline Reference & $\begin{array}{c}\text { Road } \\
\text { Conditioning }\end{array}$ & $\begin{array}{c}\text { Vehicle } \\
\text { Model } \\
\text { Type }\end{array}$ & Velocity & $\begin{array}{c}\text { Regenerated } \\
\text { Power }\end{array}$ \\
\hline$[5]$ & A class & Minibus & $30 \mathrm{~km} / \mathrm{h}$ & $2.08 \mathrm{~W}$ \\
& B class & $30 \mathrm{~km} / \mathrm{h}$ & $8.33 \mathrm{~W}$ \\
\hline$[6]$ & A class & $\begin{array}{c}\text { Hybrid } \\
\text { Electrical } \\
\end{array}$ & - & $10 \mathrm{~W}$ \\
& B class & $\begin{array}{c}\text { Vehicle } \\
\end{array}$ & & $50 \mathrm{~W}$ \\
\hline$[7]$ & C class & $\begin{array}{c}\text { Passenger } \\
\text { Car }\end{array}$ & $60 \mathrm{mile} / \mathrm{h}$ & $300 \mathrm{~W}$ \\
\hline
\end{tabular}

The following are the advantages of using the regenerative model

- The system utilizes the waste energy to generate electricity. Therefore, the electrical power generation is purely based on renewable energy model.

- The whole design is simple yet very effective. The whole idea started with a mere observation and is highly potential in terms of future applications.

- The method is highly economical and promising once incorporated in large scale production.

\section{CONCLUSION}

The study shows that it is practical to extract energy from the movement of shock absorbers, which otherwise was just lost in the form of heat. The introduction of a regenerative model in conventional suspension enhances the energy utilization rate of the vehicle, thereby, increasing the comprehensive performance of vehicles. The design used in the paper is limited to be used in passive systems, however, a much more efficient system can be developed for active systems. The efficiency of the system can be increased with increases in sprung mass, the height of suspension, higher gear ratios, higher specification of dynamo, etc. It is to be noted that the concept used is just a mere start, but further study can establish higher efficient and practical ways to extract energy that otherwise is wasted.

\section{ACKNOWLEDGMENT}

The author is grateful to D.Y Patil College of Engineering for providing resources at the Department of Mechanical Engineering enable him to carry out this research work.

\section{REFERENCES}

[1] Y. Zhang, K. Huang, F. Yu, Y. Gu and D. Li, "Experimental verification of energy-regenerative feasibility for an automotive electrical suspension system," in IEEE International Conference on Vehicular Electronics and Safety, , Beijing, China,, 13-15 December 2007.

[2] R. Goldner, P. Zerigian and J. Hull, " A preliminary study of energy recovery in vehicles by using regenerative magnetic shock absorbers," in Government/Industry Meeting, Washington, DC, USA,14-16 May 2001. 14-16 May 2001.

[3] K. Wani, "Suspension Based Kinetic Energy Recovery System.," International Journal of Mechanical Engineering and Technology, 2016.

[4] D. S. N. \&. K. V. Adeishvili, "Method for controlled extraction of energy stored in a capacitor," Tech. Phys. 44, 977-979. https://doi.org/10.1134/1.1259416, 1999.

[5] Z. Han, G. Xuexun, F. Zhigang, H. Zhang, X. Guo, Z. Fang, L. Xu and J Zhang, "Potential Energy Harvesting Analysis and Test on EnergyRegenerative Suspension System.," J. Vib. Meas. Diagn., 2015.

[6] M. Montazerigh and M. Soleymani, "Investigation of the Energy Regeneration of Active Suspension System in Hybrid Electric Vehicles," EEE Trans. Ind. Electron., 2010.

[7] Z. Zhang, X. Zhang, W. Chen, Y. Rasim, W. Salman, H. Pan, Y. Yuan and C. Wang, "A high-efficiency energy regenerative shock absorber using supercapacitors for renewable energy applications in a rangeextended electric vehicle.," .Appl. Energy, 2016.

[8] Y. J. ,. H. Z. ,. J. Z. ,. G. Z. a. L. Z. Xueying Lv, "Research Review of a Vehicle Energy-Regenerative". 